\title{
Research on Reasonable Lag Time of Gob-side Entry Driving in Deep Mine Based on On-line Monitoring of Lateral Stress and Deformation of Working Face
}

\author{
Luyi Xing \\ State Key Laboratory of Mining \\ Disaster Prevention and Control \\ Co-founded by Shandong Province and \\ the Ministry of Science and Technology, \\ Shandong University of Science and \\ Technology \\ College of Mining and Safety \\ Engineering, Shandong University of \\ Science and Technology \\ Qingdao, China \\ xingluyi125@163.com
}

\section{Haiyu $\mathrm{Ji}$}

State Key Laboratory of Mining

Disaster Prevention and Control

Co-founded by Shandong Province and the Ministry of Science and Technology,

Shandong University of Science and Technology

College of Mining and Safety

Engineering, Shandong University of Science and Technology Qingdao, China

731455669@qq.com

\author{
Yongiie Yang \\ State Key Laboratory of Mining \\ Disaster Prevention and Control \\ Co-founded by Shandong Province and \\ the Ministry of Science and Technology, \\ Shandong University of Science and \\ Technology \\ College of Mining and Safety \\ Engineering, Shandong University of \\ Science and Technology \\ Qingdao, China \\ yyj.6125@163.com \\ Yandong Zhang \\ State Key Laboratory of Mining \\ Disaster Prevention and Control \\ Co-founded by Shandong Province and \\ the Ministry of Science and Technology, \\ Shandong University of Science and \\ Technology \\ College of Mining and Safety \\ Engineering, Shandong University of \\ Science and Technology \\ Qingdao, China \\ 986221677@qq.com
}

\author{
Jiakun Lv \\ State Key Laboratory of Mining \\ Disaster Prevention and Control \\ Co-founded by Shandong Province and \\ the Ministry of Science and Technology, \\ Shandong University of Science and \\ Technology \\ College of Mining and Safety \\ Engineering, Shandong University of \\ Science and Technology \\ Qingdao, China \\ 717836201@qq.com
}

Abstract-The determination of reasonable lag time is the key to make the gob-side entry driving away from the violent mining of the working face. In this paper, the geological and mining conditions of the No.7432 Working Face in Kongzhuang Coal Mine is taken as the research background. Using an independently developed infrared acquisition and observation system consisting of a single beam with multi-line and multi-point (stress and deformation) sensors, the long-term and continuous on-line monitoring of the stress and deformation (displacement) change regulation of the lateral coal body in the No.7432 Working Face headentry during the whole process of mining was carried out. The monitoring results demonstrated that it took at least 5 months for the main roof to keep stable, which was the best lag time of the roadway driving along the goaf. The valuable technical experience and practical basis can be provided for the analysis and determination of reasonable lag time for gob-side entry driving in similar conditions, which is of great significance for relaxing the tense prospect of mining and driving continuance, and improving the comprehensive benefits of the coal mine.

Keywords-mining engineering, gob-side entry driving, lateral coal body, stress and deformation, on-line monitoring, reasonable lag time

\section{INTRODUCTION}

Gob-side entry driving with small coal pillar has played a great role in relaxing the tense prospect of mining and driving continuance, and improving the comprehensive benefits of mine. During the last working face mining, the overlying strata of the stope will be subjected to intensive movement due to mining. If the tunneling time is too early, the overlying strata movement of the stope will not be stable. The surrounding rock of the roadway is obviously affected by the overlying strata movement, and the deformation is serious, which is not conducive to the maintenance of the roadway. If the tunneling time is too late, it will affect the recovery work of the next working face, delay the construction period, and reduce the economic benefits of the mine. Therefore, determining the reasonable lag time of roadway driving is the key to the successful implementation of the technical advantages of gob-side entry driving.

Determining the lag time for excavation must be established on the basis of comprehensively mastering the dynamic distribution law of lateral coal body support pressure on the working face and the main roof motion characteristics. Many scholars have carried out a large amount of research work using theoretical calculations and numerical simulations, or even empirical analogies or 
estimates, obtaining many useful researches[1-8]. On the basis of the dynamic change characteristics of the roof structure of the goaf in both sides of the working face, Fuxing Jiang et al. established the general model of the support pressure of the coal body on the isolated island working face, who put forward the formula for calculating the abutment pressure of the coal face on the island working face. At the same time, the relationship between the maximum abutment pressure and the advanced distance of the working face during the insufficient mining stage is studied by means of mechanical method[9,10]. Through the field stress and microseismic monitoring, Shuwen Wang et al. analysed the stage and interval characteristics of the vertical stress of the lateral coal body in the goaf in the direction of the working face and the direction of the slope. Based on the measured data, the rule of vertical stress and elastoplastic evolution of coal seams in different stages and intervals were obtained[11]. On line monitoring the law of lateral ore pressure in the goaf of 3801 special thick and hard coal seam fully mechanized coal caving face of the Water Curtain Cave Coal Mine, Yunhai Cheng et al. established the overlying rock structure model of the lateral direct top "rock waste" structure, the main roof "rock beam" structure and the stress model of the roadway isolation wall in the goaf, revealing the characteristics of the lateral mine pressure in the working face[12]. Yongxiang $\mathrm{Xu}$ et al. studied the distribution characteristics of the lateral abutment pressure of fully mechanized top coal caving face in extremely thick coal seam in Tashan mining area by similar material simulation method[13]. Guangxiang Xie et al. combined the geological conditions and technical conditions of the fully mechanized top coal caving face of Xieqiao Coal Mine, and monitored the law of stress variation of coal pillar in the section by borehole stress meter[14,15]. Fan Shengqiang Fan et al. studied the distribution characteristics of supporting pressure distribution in the lagging working face of Yanzhou mining area by combining theoretical analysis, numerical simulation and field measurement[16].

Although many scholars have done a lot of research work on the distribution characteristics of the abutment pressure of stope, there are still few actual measurements of the lateral coal body supporting pressure and the main roof movement development process in the stope, especially the continuous on-line monitoring of the stress and deformation (displacement) change regulation of the lateral coal body of the goaf. Due to the limitations of laboratory conditions, many physico-mechanical parameters of rock are difficult to be accurately determined, and the complexity and particularity of the specific geology and mining conditions at the site are irreplaceable. As a matter of fact, it is important to monitor the stress size at different positions in the side direction coal wall and the dynamic change of the corresponding displacement of the lateral coal body during the mining. Therefore, it is possible to accurately analyze and grasp the distribution of lateral supporting pressure and the time for the stable movement of the main roof (i.e. the time of the main roof rock beam sinking and sinking with the gangue). Only in this way can the scientific basis for guiding the reasonable lag time of driving along roadways be obtained.

\section{GeOlOGiCAL Situation OF CONSTRUCTION}

No.7 coal seam in the NO.IV1 mining area of the hole coals mine is located at the $-785 \sim-1000 \mathrm{~m}$ levels (the ground elevation is about $32 \mathrm{~m}$ ), which belongs to the typical deep mining. There is a fault distribution in No.7432 fully mechanized caving face, the thickness of coal seam is $3.40 \sim$ $5.00 \mathrm{~m}$, the average thickness is $4.35 \mathrm{~m}$, the dip angle of the coal seam is 18 to 23 degrees, the average is 21 degrees, and the diagram of mining engineering plane is shown in Fig. 1.

The single face longwall mining method and fully mechanized top coal caving method were adopted in the working face. The mining height is $2.40 \mathrm{~m}$, and the proportion of the two methods is $1: 1$. The thickness of the immediate roof is $11.45 \mathrm{~m}$, consisting of $1.70 \mathrm{~m}$ argillaceous sandstone, $1.60 \mathrm{~m}$ siltstone, $6.66 \mathrm{~m}$ medium grain sandstone and $1.45 \mathrm{~m}$ sandy mudstone. The main roof is made of $10.73 \mathrm{~m}$ medium grain sandstone and the floor is made of $3.12 \mathrm{~m}$ sandy mudstone.

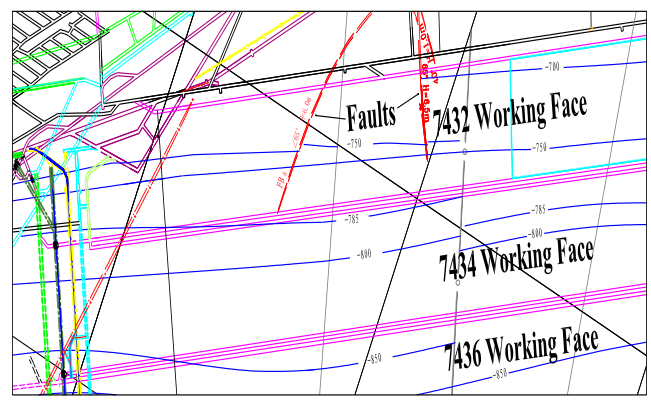

Fig. 1. Diagram of mining engineering plane.

\section{OBSERVATION INSTRUMENT AND SURVEY AREA LAYOUT}

\section{A. Observation system and method}

Observation system

Since the No.7432 Working Face is the first mining face of the NO.IV1 mining area, both sides of the mining roadway are solid coal, and there are no adjacent lanes such as crossheading and other preparatory lanes. After the working face is propelled, the goaf is closed due to the immediate roof and the personnel can not enter. Therefore, the traditional method of monitoring the abutment pressure is not applicable for the site. Therefore, a single beam with multi-line and multi-point (stress and deformation) sensor was developed, and an infrared acquisition and observation system were adopted to measure the motion state of the roof in the goaf rear area of the working face. The system includes the mine-used I. S. optical terminal (KTG12), mine-used I. S. borehole stress sensor (GZY60W), borehole stress meter $(\mathrm{GZY} 60 \mathrm{H})$, surrounding rock mobile sensor (GUD-240), communication adapter (SP-HW), mine flameproof and I. S. uninterruptible power supply (KDW28-18), mine-used I. S. handheld collector (FCH64/2), supporting testing software (RJ-HW) and so on.

First of all, the survey area should be located in the area beyond the influence area of the advance bearing pressure on the No.7432 Working Face, drilling holes with different depths for installing borehole stress meter and surrounding rock mobile sensor on the side of the actual coal mining roadway. The instruments were connected with the collection station outside the $400 \mathrm{~m}$ through the communication cable. In order to ensure the reliability and safety of communicated cables, the communicated cables should be equipped with armored cables with strong tensile strength, high compressive strength and strong corrosion 
resistance. In addition, in order to prevent the damage of the gangue from the roof falling behind the working face, all communication cables and wires should be preinstalled in the high-pressure hose. Then it was embedded in the floor near the roadway side. The specific location and groove dimensions of slotting in the bottom plate were suitable for placing high-pressure rubber hoses and facilitating site construction. Finally, a floating coal was used to cover it.

\section{Observation method}

The sensor automatically collects data of stress and deformation every five minutes. The data was transferred to GZY60W type borehole stress sensor and GUD-240 type surrounding rock mobile sensor and then converted to digital signal. The data was then transmitted to the KTG12 optical transceiver through communication cable for processing and storage. The FCH64/2 handheld collector was used to collect data regularly, and the SP-HW type communication adapter transfered data to the in-hole computer for software display and statistical analysis.

\section{B. Survey area layout}

This monitoring plan had a total of $1 \#$ and $2 \#$ layouts. The 1\# survey area was arranged beyond the abutment pressure of the headentry in the working face, and it was at a distance of $400 \mathrm{~m}$ from the acquisition station. In order to prevent accidents in the $1 \#$ survey area, and ensure the continuous observation of stress and displacement as far as possible. The 2\# survey area was arranged at about $50 \mathrm{~m}$ in front of the 1\# survey area. The distance from the acquisition station in the $2 \#$ survey area was $350 \mathrm{~m}$. Fig. 2 shows the layout of the lateral coal body stress displacement and coal displacement measurement zone along the headentry of No.7432 fully mechanized caving face.

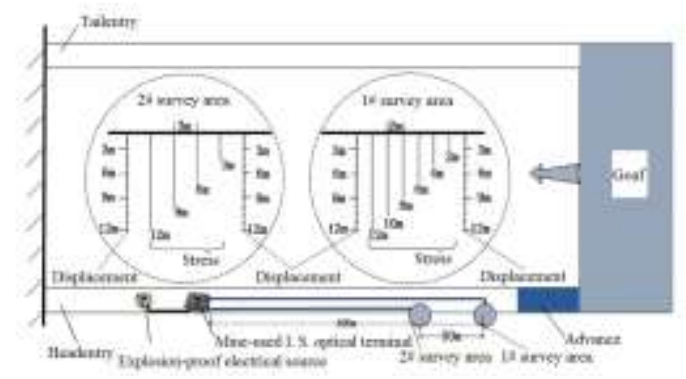

Fig. 2. Layout of stress and displacement survey area in the side of No.7432 Working Face.

\section{Stress measurement point layout}

Six boreholes were arranged in the lower side of the roadway in the $1 \#$ survey area. The inward number of coal wall was $1 \#, 2 \#, 3 \#, 4 \#, 5 \#$ and $6 \#$ in turn. The horizontal spacing of the drilling holes was $2 \mathrm{~m}$, and the height of the hole was 0.5 to $1.5 \mathrm{~m}$ (according to the specific situation of the site). The hole depth was $2 \mathrm{~m}, 4 \mathrm{~m}, 6 \mathrm{~m}, 8 \mathrm{~m}, 10 \mathrm{~m}, 12 \mathrm{~m}$ in order. Four drill holes were arranged under the roadway in the 2\# survey area. The borehole was numbered 7\#, 8\#, 9\#, $10 \#$ in turn, and the horizontal distance between the holes was $3 \mathrm{~m}$. The height of the hole was 0.5 to $1.5 \mathrm{~m}$ (according to the specific situation of the site), and the depth of the hole was $3 \mathrm{~m}, 6 \mathrm{~m}, 9 \mathrm{~m}$ and $12 \mathrm{~m}$ in turn.

\section{Displacement measuring point layout}

On the both sides of the two survey areas, two sets of four-point surrounding rock movement sensors were arranged symmetrically, and the opening height was 0.5 to $1.5 \mathrm{~m}$ from the floor (determined according to site conditions). The hole depth was $12 \mathrm{~m}$.

The surrounding rock mobile sensors were numbered $11 \#, 12 \#, 13 \#$ and 14\# according to the order of installation time. The number of mobile points of each mobile sensor was 4 , and the depth of the base points was $12 \mathrm{~m}, 9 \mathrm{~m}, 6 \mathrm{~m}$ and $3 \mathrm{~m}$ respectively.

\section{MEASUREMENT AND ANALYSIS OF THE VARIATION OF STRESS AND DEFORMATION (DISPLACEMENT) ON THE LATERAL COAL BODY OF THE WORKING FACE}

Owing to the complexity of specific geological condition, it's difficult to determine mechanical parameters of coal roof and floor and boundary conditions. Adopting the methods of theoretical analysis, experience analogies and numerical simulation are difficult to accurately infer the time of strenuous exercise stable of working face. Only through actual measurement and analysis of specific lateral stress and deformation of working face can accurately determine the motion state and strenuous exercise stable (rotating, subsiding and contacting gangue) time of main roof, determining reasonable lag time of driving.

\section{A. Dynamic change characteristics of main roof rock beam state in the process of mining}

Under the guidance of the core theory of "Overlying Strata Movement" in mining pressure and strata control, utilizing infrared acquisition observation system consisting of a single beam with multi-line and multi-point (stress and deformation) sensors, the dynamic change process of lateral coal body deformation degree at different mining stages can be divided into three development stages, which are the slowly increasing stage of deformation under the influence of advanced support pressure, the rapidly increasing stage of deformation under the influence of strenuous movement of the roof, and the gradually increasing and being stable stage of deformation during gangue compaction in goaf, as shown in Fig. 3.

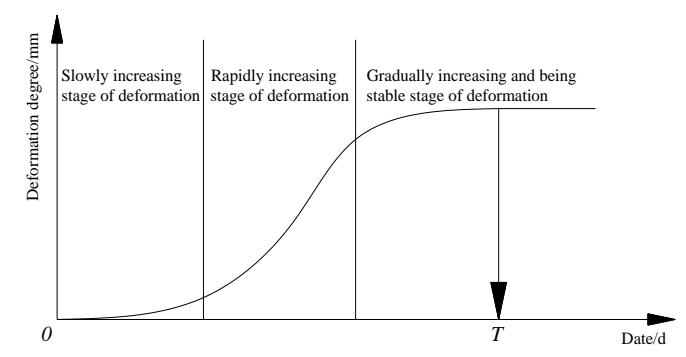

Fig. 3. Law of lateral coal body displacement with the date.

Slowly increasing stage of deformation

When far from the working face, that is, outside the range of the advanced support pressure, the coal that locating in the lateral and the front of working face is under the action of original rock stress (advancing crossheading breaks stress equilibrium due to excavation). At this time, it was not affected by the advanced support pressure of the working face, and the deformation degree of coal deformation sensor is very small. When the working face is pushed to the point where the measuring point is affected by the advanced support pressure, the stress peaks in lateral coal body. The upper main roof in this stage is still relatively stable. The span of the working face has not reached the 
limit span of the main roof, and the main roof is not broken, as shown in Fig. 4(a).

\section{Rapidly increasing stage of deformation}

When the main roof develops to its limit span, that is, when the tensile stress caused by the bending moment at the rock beam end of the main roof exceeds its tensile strength, the main roof rock beam breaks in front of the working face. After breaking, it is bounded by fracture lines, dividing support pressure into internal and external stress fields. At this point, although the main roof is still in a equilibrium state of temporary articulation supported by the coal wall, but there will be gradually rotary sinking motion. Therefore, the deformation degree of the coal deformation sensor will obviously increase. When the working face advances near or after the fracture line, the main roof rock beam will lose the support of the coal wall. When the temporary articulation balance supported by the coal wall is broken, a violent rotary sinking motion will be taken place. Due to the rotary, sinking and extrude of the main roof, coal will be further broken and the deformation degree of the deformation sensor will increase sharply. Pre and post the mining, the main roof rock beam is in a significant motion stage. Before rotating, subsiding and contacting gangue, the main roof causes a very obvious underground pressure in the rock mass around the working face. The motion pattern is shown in Fig. 4(b).

Gradually increasing and being stable stage of deformation

As the working face continues to advance, the main roof will rotate, subside and contact the gangue. At this time, the falling rock is relatively loose and broken of the immediate roof, and the main roof rock beam will obviously compress the loose broken falling rock, causing a more obvious deformation of the lateral coal body. The deformation degree of the coal deformation sensor at this stage will still increase to a certain extent. As the working face continues to advance, the main roof rock beam further compresses the gangue behind the working face. When the working face is pushed over a certain distance of the survey area, the main roof rock beams will basically compact the gangue and no longer have obvious motion. At this moment, the deformation degree of the coal deformation sensor will be no longer significantly changed. The main roof rock beam motion pattern at this stage is shown in Fig. 4(c). The time corresponding to the inflection point where the deformation degree stabilizes (the point $T$ in Fig. 3) can be used as a criterion for the reasonable lag time for gob-side entry driving.

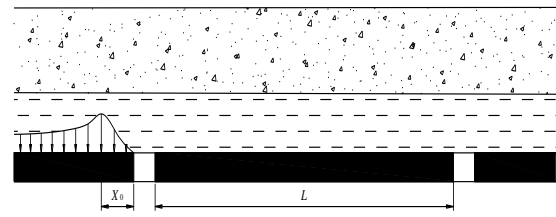

(a) Relatively stable state when the main roof is not broken

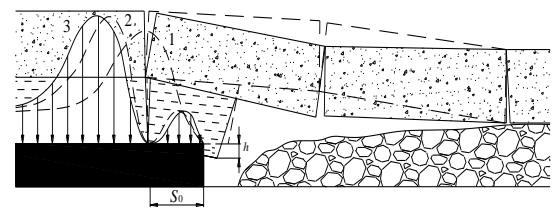

(b) The strenuous movement state of the mian roof rotary sinking

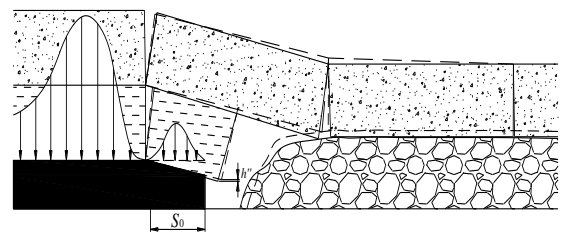

(c) The stable state after the main roof touches the gangue

Fig. 4. Dynamic change characteristics of main roof rock beam state in the process of mining[17].

\section{B. Measured results of motion stability time (distance) of main roof rock beam in working face}

In view of the extremely complex on-site conditions, the speed of the No.7432 Working Face was unlikely to be consistent. Therefore, the relationship between the advancing distance and the actual time of the working face was drawn (See Fig. 5).

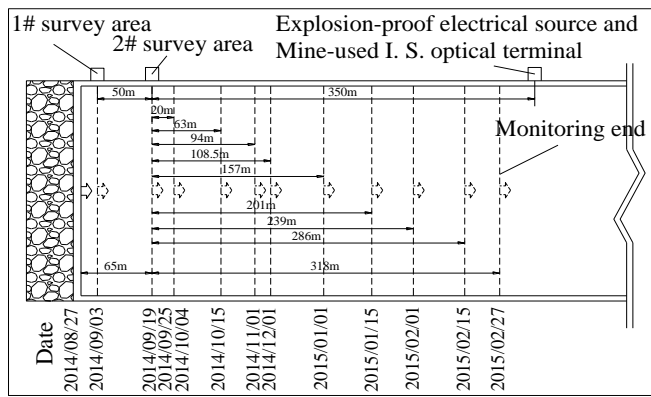

Fig. 5. No.7432 Working Face position time relation diagram at different stages of mining.

After the installation of the observing system, the monitoring will begin on August 27, 2014. Taking into account that the amount of data were large and some of the measuring points were roughly the same, only $7 \#(3 \mathrm{~m}), 8 \#$ $(6 \mathrm{~m}), 9 \#(9 \mathrm{~m})$ and $10 \#(12 \mathrm{~m})$ stress measurement points in the $2 \#$ survey area were selected and only $13 \#$ (base point depth was $3 \mathrm{~m}, 6 \mathrm{~m}, 9 \mathrm{~m}, 12 \mathrm{~m}$ ) displacement measurement points were used to analyze. The data of each measuring point were stored and processed by computer, and the following curves were drawn (See Fig. 6).

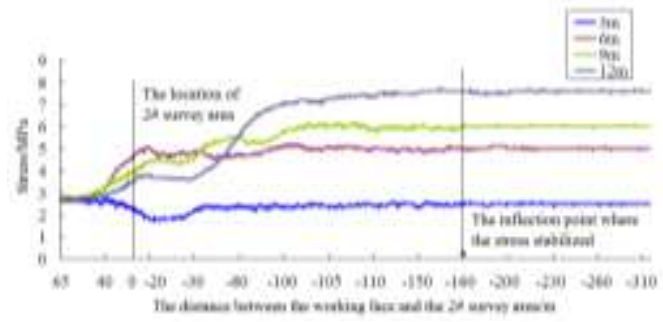

(a) Stress-Distance relation curves

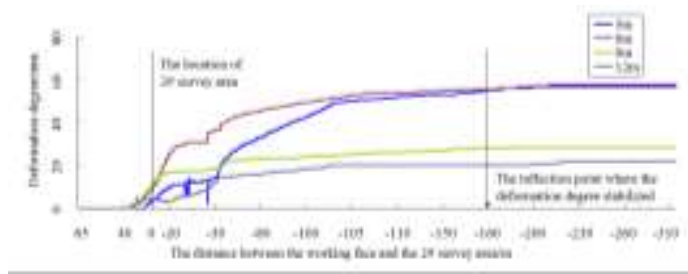

(b) Deformation degree-Distance relation curves

Fig. 6. Stress-Distance and Deformation degree-Distance relation curves of different measuring points. 
The positive value in Fig. 6 represents the 2\# survey area was in the front of the working face, and the negative value represents the 2\# survey area was in the back of the working face. It can be seen from the change of stress and deformation (displacement) at each measuring point. When the working face was advanced over the first $40 \mathrm{~m}$, the stress of each measuring point would begin to change significantly. When the working face was advanced $20 \mathrm{~m}$ from the $2 \#$ surveying area, the stress and displacement of each measuring point would change rapidly. When advancing $90 \mathrm{~m}$ from the $2 \#$ surveying area, the changes of each point would slow down. Until the working face passed 160m from the $2 \#$ surveying area, the stress and deformation of each measuring point would remain basically unchanged. It was shown that the motion of the main roof rock beam in the goaf had been stable. From the time perspective, on September 3, 2014, the working face was advanced to 2\# survey area. The date of the working face advanced over $160 \mathrm{~m}$ was January 1, 2015. However, due to the 9 days production break from September 25, 2014 to October 4, 2014, large faults encountered in the working face from November 1, 2014 to December 20, 2014, the working face was advanced slowly. Therefore, if the advancing speed of the normal working face was $2.5 \mathrm{~m} / \mathrm{d}$, the actual distance that the 2\# survey area behind working face should be more than $160 \mathrm{~m}$ when the motion of the main roof in the goaf was stable, and reached more than $300 \mathrm{~m}$. Therefore, the lag distance at which the roof movement of the No.7432 Working Face tended to be stable was not less than $300 \mathrm{~m}$, and the lag time was not less than 4 months.

The coal seam, roof and floor and geological structure conditions are different in different working faces. At the same time, after the large-scale stopping of the No.IV1 mining area, the coverage of the overlying strata movement will increase. The time for motion stability of the main roof will also be extended to different degrees. Considering the safety, the reasonable lag time for gob-side entry driving in the adjacent mining area of No.IV1 mining area should not be less than 5 months, and the lag distance of the working face was not less than $300 \mathrm{~m}$.

\section{CONCLUSION}

(1) Reasonable lag time is the key to make the gob-side entry driving with small coal pillar away from the violent mining of the working face. Long-term on-line monitoring of lateral support pressure distribution characteristics and coal body deformation law in the front and the back (especially the back) of the working face is of great guiding significance for the judgment of the time for the stable movement of the main roof and the accurate determination of the reasonable lag time for gob-side entry driving.

(2) The judgment of the motion state of the main roof rock beam must be established on the basis of comprehensively mastering the support pressure distribution law around the stope and the characteristics of lateral coal body deformation. The characteristics of the lateral coal body stress and deformation better reflect the movement state of the main roof rock beam. Therefore, the dynamic change process of lateral coal body deformation degree at different mining stages can be divided into three stages, which are slowly increasing stage of deformation, rapidly increasing stage of deformation, and gradually increasing and being stable stage of deformation.
(3) Using an independently developed infrared acquisition and observation system consisting of a single beam with multi-line and multi-point (stress and deformation) sensors, the long-term and continuous on-line monitoring of the stress and deformation (displacement) regulation of the lateral coal body in the headentry of No.7432 Working Face during the whole process of mining was carried out. The monitoring results show that the reasonable lag time for the gob-side entry driving in the adjacent mining area of No.IV1 mining area should not be less than 5 months when the upper working face was extracted. The infrared on-line monitoring method of lateral coal body stress and deformation proposed in this paper is of great practical significance for determining the reasonable lag time of the gob-side entry driving.

\section{ACKNOWLEDGEMENT}

In this paper, the research was sponsored by the National Natural Science Foundation of China (Project No. 51379116 and 51574156), Tai'shan Scholar Talent Team Support Plan for Advantaged \& Unique Discipline Areas and Program for Graduate Science and Technology Innovation of Shandong University of Science and Technology (Project No. SDKDYC 170204).

\section{REFERENCES}

[1] Z. Q. Song, "Practical method of mine pressure control," China University of Mining and Technology Press, 1988.

[2] Y. L. Tan, S. L. Wu, Z. D. Yin, J. G. Ning, S. T. Gu, et al, "Ground pressure and strata control," Beijing: China Coal Industry Publishing House, 2008

[3] Y. L. Tan, X. S. Liu, J. G. Ning, and C. L. Tian, "Front abutment pressure concentration forecast by monitoring cable-forces in the roof," International Journal of Rock Mechanics and Mining Sciences, 2015, vol. 77, pp. 202-207.

[4] X. L. Du, H. W. Song, and J. Chen, "Analysis of effect of dynamic mining pressure on surrounding rock stress of nearby entry", Journal of China Three Gorges University, 2011,vol. 31, pp. 51-54.

[5] D. C. Wang, S. C. Li, Q. Wang, W. T. Li, F. Q. Wang, et al, "Experimental study of reasonable coal pillar width in fully mechanized top coal caving face of deep thick coal seam," Chinese Journal of Rock Mechanics and Engineering, 2014, vol. 33, no.1, pp. 539-548.

[6] T. X. Wang, C. X. Liu, and X. P. Wang, "Flac3D numerical simulation and radar detection of lateral abutment pressure distribution of isolated coal pillar," Chinese Journal of Rock Mechanics and Engineering, 2002, vol. 21, no. S2, pp. 2484-2487.

[7] X. Z. Hua, S. Liu, Z. H. Liu, W. H. Zha, and Y. F. Li, "Research on strata pressure characteristic of gob-side entry driving in island mining face and its engineering application," Chinese Journal of Rock Mechanics and Engineering, 2011, vol. 30, no. 8, pp. 1646-1651.

[8] C. Y. Liu, B. X. Huang, X. J. Meng, P. J. Yang, and L. G. Chen, "Research on abutment pressure distribution law of overlength isolated fully-mechanized top coal caving face," Chinese Journal of Rock Mechanics and Engineering, 2007, vol. 26, no. S1, pp. 2761-2766.

[9] F. X. Jiang, G. Cheng, and Y. Feng, "Research on coal overall instability of isolated working face with irregular gobs on both sides," Chinese Journal of Rock Mechanics and Engineering, 2015, vol. 34, no. S2, pp. 4164-4170.

[10] F. X. Jiang and Q. H. Ma, "Mechanical solution of the maximum point of dynamic abutment pressure under deep long-wall working face," Journal of China Coal Society, 2002, vol. 27, no. 3, pp. 273-275.

[11] S. W. Wang, D. B. Mao, J. F. Pan, J. G. Chen, F. Chen, et al, "Measurement on the whole process of abutment pressure evolution and microseismic activities at the lateral strata of goaf," Journal of China Coal Society, 2015, vol. 40, no. 12, pp. 2772-2779. 
[12] Y. H. Cheng, F. X. Jiang, and J. L. Pang, "Characteristics and application of lateral pressure in goaf of fully mechanized top coal caving in extra thick coal seam," Journal of China Coal Society, 2012, vol. 37, no. 7, pp. 1088-1093

[13] Y. X. Xu, H. M. Li, K. L. Wang, and R. F. Yuan, "Study on lateral support pressure distribution of fully-mechanized coal mining face in ultra thick seam," Coal Science and Technology, 2014, vol. 39, no. 11, pp. 26-28.

[14] G. X. Xie, K. Yang, and J. C. Chang, “Analysis on site measurement of support pressure distribution law for seam of fully mechanized longwall top coal caving mining," Coal Science and Technology, 2006 , vol. 34 , no. 3 , pp. 1-3.
[15] G. X. Xie, K. Yang, and Q. M. Liu, "Study on distribution laws of stress in inclined coal pillar for fully-mechanized top-coal caving face," Chinese Journal of Rock Mechanics and Engineering, 2006, vol. 25, no. 3, pp. 545-549.

[16] S. Q. Fan, X. Z. Zou, and G. L. Liu, "Distributing discipline of abutment pressure behind working face," Journal of Heilongjiang Institute of Science and Technology, 2006, vol. 16, no. 2, pp. 78-81.

[17] H. Shi and F. X. Jiang, "Structural theories of overlying strata in longwall faces and their new development," Journal of Shandong University of Science and Technology (Natural Science), 2005, vol. 24 , no. 1 , pp. $21-25$. 